\title{
A Modified Eyring Equation for Modeling Yield and Flow Stresses of Metals at Strain Rates Ranging from $10^{-5}$ to $5 \times 10^{4} \mathrm{~s}^{-1}$
}

\author{
Ramzi Othman \\ Mechanical Engineering Department, Faculty of Engineering, King Abdul-Aziz University, P.O. Box 80248, Jeddah 21589, Saudi Arabia \\ Correspondence should be addressed to Ramzi Othman; rothman1@kau.edu.sa \\ Received 12 March 2015; Accepted 23 June 2015 \\ Academic Editor: Gianluca Percoco \\ Copyright (C) 2015 Ramzi Othman. This is an open access article distributed under the Creative Commons Attribution License, \\ which permits unrestricted use, distribution, and reproduction in any medium, provided the original work is properly cited.

\begin{abstract}
In several industrial applications, metallic structures are facing impact loads. Therefore, there is an important need for developing constitutive equations which take into account the strain rate sensitivity of their mechanical properties. The Johnson-Cook equation was widely used to model the strain rate sensitivity of metals. However, it implies that the yield and flow stresses are linearly increasing in terms of the logarithm of strain rate. This is only true up to a threshold strain rate. In this work, a three-constant constitutive equation, assuming an apparent activation volume which decreases as the strain rate increases, is applied here for some metals. It is shown that this equation fits well the experimental yield and flow stresses for a very wide range of strain rates, including quasi-static, high, and very high strain rates (from $10^{-5}$ to $5 \times 10^{4} \mathrm{~s}^{-1}$ ). This is the first time that a constitutive equation is showed to be able to fit the yield stress over a so large strain rate range while using only three material constants.
\end{abstract}

\section{Introduction}

The steel and metallic materials are largely used in several industrial fields, for example, automobile, naval, aeronautical, and military industries. In these applications, transportation vehicles have to be designed against impact loads. Thus, developing constitutive equations that take into account the strain rate sensitivity of metals is of major importance.

The split Hopkinson bar was largely applied to evaluate the strain rate sensitivity of materials at high strain rates; that is, $\dot{\varepsilon} \sim<5000 \mathrm{~s}^{-1}[1-3]$. At very high strain rates $(\dot{\varepsilon}>\sim$ $5000 \mathrm{~s}^{-1}$ ), the direct-impact Hopkinson bar is now increasingly used $[4,5]$. Based on the available experimental data, several constitutive equations were proposed in the open literature [6-9]. Johnson and Cook [10] have proposed a phenomenological equation that includes hardening, temperature, and strain rate effects. This equation has been widely used [11-13] and included in several commercial finiteelement software types; this is mainly due to the reduced number of constants that it used and the separation of the hardening, temperature, and strain rate effects. It was then applied to model the strain rate sensitivity mainly for metallic alloys as for titanium $[14,15]$, copper [16], aluminum [17, 18], and steel [19-22] alloys.

The Johnson-Cook equation assumes that the yield and flow stresses are linearly increasing in terms of the logarithm of strain rate. Nevertheless, this assumption is mostly valid up to a threshold strain rate. The strain rate sensitivity highly increases at high strain rates [23, 24], indeed. Several modifications have then been proposed to extend the validity of the Johnson-Cook model up to the very high strain rate range [24-27].

The original Johnson-Cook model uses two constants to take into consideration the strain rate sensitivity. The modified Johnson-Cook equations involve at least four constants in order to catch the stress behavior at very high strain rate. Recently, El-Qoubaa and Othman [28] proposed a modified Eyring equation [29] to model the strain rate sensitivity of the polyetheretherketone's yield stress. Within the framework of the Eyring theory, yielding is a thermally activated process. Ree and Eyring [30] used relaxation processes. Fotheringham et al. [31,32] introduced the idea of the cooperative motion of polymer chain segments. Richeton et al. [33] used the cooperative motion theory and introduced the Arrhenius law for 
the horizontal and vertical shifts. El-Qoubaa and Othman $[28,34]$ used an apparent activation volume which is decreasing for increasing strain rate. Their equation involves three material constants.

In this work, El-Qoubaa and Othman's equation is examined regarding the yield stress and the flow stress at a given plastic strain, of several metals. Besides, the methodology, to obtain a reasonable first guess of the materials constants, is detailed.

\section{Constitutive Equation}

Johnson and Cook [10] have proposed that the flow stress of metals is obtained in the following form:

$$
\sigma=\left(A+B \varepsilon_{p}^{n}\right)\left(1+C \ln \left(\frac{\dot{\varepsilon}}{\dot{\varepsilon}_{0}}\right)\right)\left(1-\left(\frac{T-T_{r}}{T_{m}-T_{r}}\right)^{m}\right),
$$

where $\varepsilon_{p}, \dot{\varepsilon}, \dot{\varepsilon}_{0}, T, T_{r}$, and $T_{m}$ are the plastic strain, strain rate, reference strain rate, temperature, room temperature, and melting temperature, respectively, and $A, B, C, n$, and $m$ are four material constants. The yield stress, at room temperature, is obtained by considering $\varepsilon_{p}=0$ and $T=T_{r}$. Thus,

$$
\sigma_{y}^{J C}=A\left(1+C \ln \left(\frac{\dot{\varepsilon}}{\dot{\varepsilon}_{0}}\right)\right) \text {. }
$$

With no loss of generality, the reference strain $\dot{\varepsilon}_{0}$ can be fixed to $1 \mathrm{~s}^{-1}$. Consequently, two materials constants, namely, $A$ and $C$, are needed to predict the strain rate sensitivity of metals' yield stress. Similarly, two constants are needed to predict the strain rate sensitivity of the flow stress at a given plastic strain.

Even though the Johnson-Cook equation is a phenomenological model, it can find some foundation in the work of Eyring [29] who argued that yielding is a thermally activation process. In this framework, the following equation for the yield stress is established:

$$
\frac{\sigma_{y}^{E}}{T}=A_{\alpha}\left(\frac{Q_{\alpha}}{R T}+\ln \left(2 C_{\alpha} \dot{\varepsilon}\right)\right)
$$

where $R$ is the universal gas constant, $A_{\alpha}$ and $C_{\alpha}$ are two material constants, and $Q_{\alpha}$ is the activation energy of the $\alpha$ transition. The Eyring equation can also be rewritten as

$$
\sigma_{y}^{E}=\sigma_{0}+\frac{k T}{V_{0}} \ln \left(\frac{\dot{\varepsilon}}{\dot{\varepsilon}_{0}}\right),
$$

where $k$ is the Boltzmann constant. Here also, two constants $\sigma_{0}$ and $V_{0}$ are needed to define the strain rate sensitivity of the yield stress. $\sigma_{0}$ is yield stress at a strain rate $\dot{\varepsilon}=\dot{\varepsilon}_{0}=1 \mathrm{~s}^{-1}$ and $V_{0}$ is the activation volume which is assumed to be constant.

El-Qoubaa and Othman [28] argued for the use of an apparent activation volume that is decreasing with increasing strain rate. More precisely, they suggested that the logarithm of the activation volume is linearly decreasing in terms of strain rate. The apparent activation volume is then written as

$$
V^{*}=V_{0} \exp \left(-\sqrt{\frac{\dot{\varepsilon}}{\dot{\varepsilon}_{c}}}\right),
$$

where $\dot{\varepsilon}_{c}$ is critical strain rate. Substituting the constant activation volume $V_{0}$ in (4) by the strain-rate-sensitive activation volume of (5) yields a new equation of the yield stress:

$$
\sigma_{y}^{M E}=\sigma_{0}+\frac{k T}{V_{0}} \exp \left(\sqrt{\frac{\dot{\varepsilon}}{\dot{\varepsilon}_{c}}}\right) \ln \left(\frac{\dot{\varepsilon}}{\dot{\varepsilon}_{0}}\right) .
$$

This modified Eyring equation needs now three constants, $\sigma_{0}$, $V_{0}$, and $\dot{\varepsilon}_{c}$, to predict the strain rate sensitivity of the yield stress. This equation can also be used to model the flow stress at a constant plastic strain.

Equation (6) has two main advantages. First, it uses a reduced number of materials constants, namely, 3 constants, whereas the modified Johnson-Cook equations use at least four constants. Second, the three material constants are easily interpretable. Hence, $\sigma_{0}$ is no more than the yield at a strain rate of $1 / \mathrm{s} . V_{0}$ is the activation volume of the $\alpha$-transition of the Eyring equation. Finally, $\dot{\varepsilon}_{c}$ separates the strain rate range in two parts. For lower strain rates $\left(\dot{\varepsilon} \ll \dot{\varepsilon}_{c}\right)$, the yield stress increases linearly in terms of the logarithm of strain rate. At high strain rates, the strain rate sensitivity highly increases with increasing strain rate. These interpretations help in establishing a methodology to obtain a first guess of these constants.

The identification of the materials constants is then divided in two steps. Firstly, a first guess is determined knowing the above interpretations of these constants. Secondly, an optimization procedure is used to better fit the experimental data. More precisely, the first-guess values of $\sigma_{0}$ and $V_{0}$ will be determined from two points in the low strain rate range assuming a linear variation of yield stress in terms of the logarithm of strain rate.

Let $\widehat{\sigma}_{1}$ and $\widehat{\sigma}_{2}$ be the yield stress measured for two strain rates $\dot{\varepsilon}_{1}$ and $\dot{\varepsilon}_{2}$, respectively, of the low strain rate range. The first guess of the constants $\sigma_{0}$ and $V_{0}$ is

$$
\begin{aligned}
\sigma_{0}^{\text {guess }} & =\frac{\widehat{\sigma}_{1} \ln \left(\dot{\varepsilon}_{2}\right)-\widehat{\sigma}_{2} \ln \left(\dot{\varepsilon}_{1}\right)}{\ln \left(\dot{\varepsilon}_{2} / \dot{\varepsilon}_{1}\right)}, \\
V_{0}^{\text {guess }} & =\frac{k T \ln \left(\dot{\varepsilon}_{2} / \dot{\varepsilon}_{1}\right)}{\widehat{\sigma}_{2}-\widehat{\sigma}_{2}},
\end{aligned}
$$

respectively.

The third constant $\dot{\varepsilon}_{c}$ will be determined from the threshold strain rate separating the thermally activated regime from the viscous regime [4]. Denoting $\widehat{\dot{\varepsilon}_{t}}$ threshold strain rate, the first guess of $\dot{\varepsilon}_{c}$ is defined as

$$
\dot{\varepsilon}_{c}^{\text {guess }}=10 \widehat{\dot{\varepsilon}_{t}} \text {. }
$$

These guesses are then considered as initial values of an optimization procedure of which the cost function is an error defined using the relative difference between the experimental yield stress and the yield stress predicted by (6). More precisely,

$$
\sigma_{0}, V_{0}, \dot{\varepsilon}_{c}=\underset{\sigma_{0}, V_{0}, \dot{\varepsilon}_{c}}{\arg \min } f\left(\sigma_{0}, V_{0}, \dot{\varepsilon}_{c}\right),
$$

where $f$ is the cost function. 


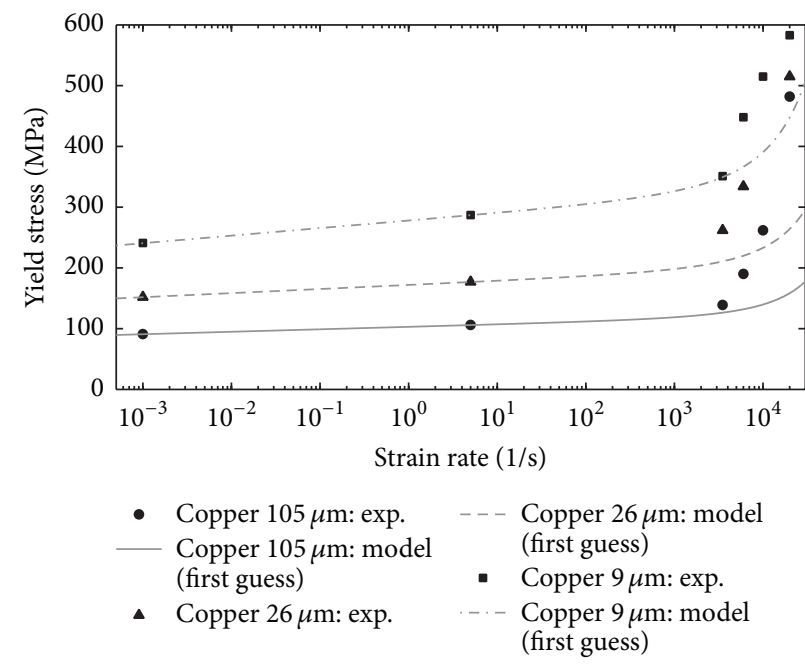

(a)

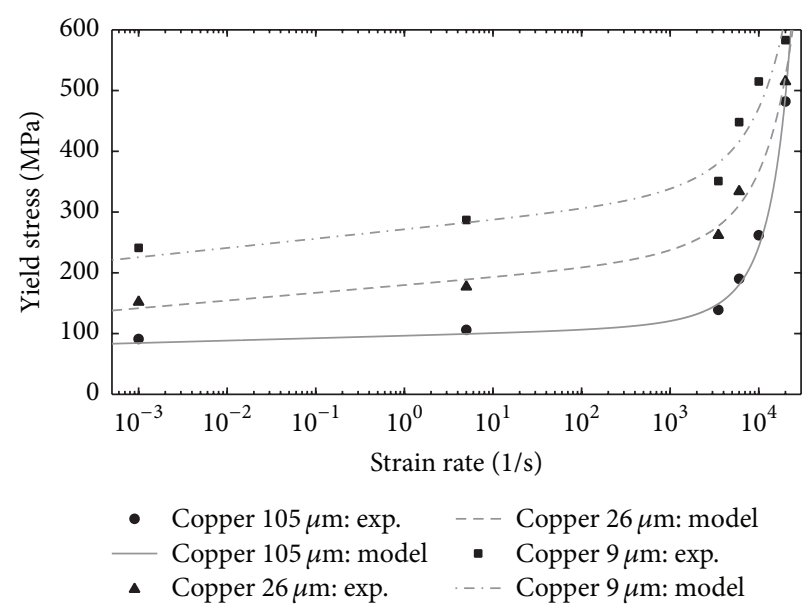

(b)

FIGURE 1: Comparison between experimental data (Couque [4]) and new modified Eyring equation for copper: (a) first-guess material constants and (b) optimized materials constants.

TABLE 1: Material constants for copper.

\begin{tabular}{lccccc}
\hline & $\sigma_{0}^{\text {guess }}(\mathrm{MPa})$ & $\sigma_{0}(\mathrm{MPa})$ & $V_{0}^{\text {guess }}\left(\mathrm{nm}^{3}\right)$ & $V_{0}\left(\mathrm{~nm}^{3}\right)$ & $\dot{\varepsilon}_{c}^{\text {guess }}\left(\mathrm{s}^{-1}\right)$ \\
\hline Copper $105 \mu \mathrm{m}$ & 103 & 96.4 & 2.31 & 2.35 & 15000 \\
Copper $26 \mu \mathrm{m}$ & 172 & 179.8 & 1.39 & 0.737 & 15000 \\
Copper $9 \mu \mathrm{m}$ & 278 & 271.6 & 0.754 & 0.612 & 15000 \\
\hline
\end{tabular}

TABLE 2: Material constants for A304L steel.

\begin{tabular}{lcccccc}
\hline & $\sigma_{0}^{\text {guess }}(\mathrm{MPa})$ & $\sigma_{0}(\mathrm{MPa})$ & $V_{0}^{\text {guess }}\left(\mathrm{nm}^{3}\right)$ & $V_{0}\left(\mathrm{~nm}^{3}\right)$ & $\dot{\varepsilon}_{c}^{\text {guess }}\left(\mathrm{s}^{-1}\right)$ & $\dot{\varepsilon}_{c}\left(\mathrm{~s}^{-1}\right)$ \\
\hline $\mathrm{A} 304 \mathrm{~L} 100 \mu \mathrm{m}$ & 336 & 347.9 & 0.827 & 0.376 & 15000 & 2946 \\
$\mathrm{~A} 304 \mathrm{~L} 10 \mu \mathrm{m}$ & 714 & 667.5 & 0.279 & 0.737 & 8000 & 2113 \\
\hline
\end{tabular}

\section{Results and Discussion}

In order to check the applicability of the new constitutive equation and the identification procedure to metals, several metallic materials are considered here. First we consider two materials, namely, copper and A304L steel, to show the quality of the first-guess material constants. Couque [4] has already reported experimental values of copper and A304L steel yield stresses for strain rates up to $\sim 20000 /$ s and $~ 10000 /$ $\mathrm{s}$, respectively. In order to achieve so high strain rates a directimpact Hopkinson bar was used [4, 5, 28].

The two-step identification procedure, detailed above, is used to determine the materials constants of (6) for three copper materials and two AA304L steels. The experimental yield stress data are obtained from Couque [4]. The first-guess and optimized material constants are given in Tables 1 and 2. Besides, the experimental yield stress reported by Couque [4] is compared to the yield stress predicted by the new modified Eyring equation (6) in Figures 1 and 2.

Using the first-guess material constants, it is easy to fit the quasi-static and intermediate strain rate data (Figures 1(a) and $2(a)$ ). It is less easy to catch the yield stress increase at high strain rates. This can be linked to the difficulty of giving a close first guess of the critical strain rate $\dot{\varepsilon}_{c}$. It is difficult to determine exactly the transition between thermally activated and viscous regimes, indeed. However, the first guess is very useful to determine initial values for the optimization problem, which is a crucial and important task. In this work, the first-guess parameters are even more important because they give close values of $\sigma_{0}$ and $V_{0}$ (Tables 1 and 2). Thus the optimization procedure will mostly concentrate on refining the value of $\dot{\varepsilon}_{c}$.

Using the optimized materials constants, the new modified Eyring equation fits well the experimental data (Figures 1(b) and 2(b)). It catches the behavior in the quasi-static as well as high strain rate ranges. The sharp increase of the yield stress at very high strain rates is well predicted up to $20000 / \mathrm{s}$ for three copper materials and up to $10000 / \mathrm{s}$ for two A304L steel materials.

Henceforth, we will concentrate on the results obtained by only the optimized materials constants. The modified Eyring equation is then used to fit the behavior of other metallic materials. Figure 3 compares the flow stress, at $10 \%$ of plastic strain, of two aluminum alloys predicted by the new modified Eyring equation to the experimental flow stress reported by Moćko et al. [35]. Equation (6) fits well the strain rate 


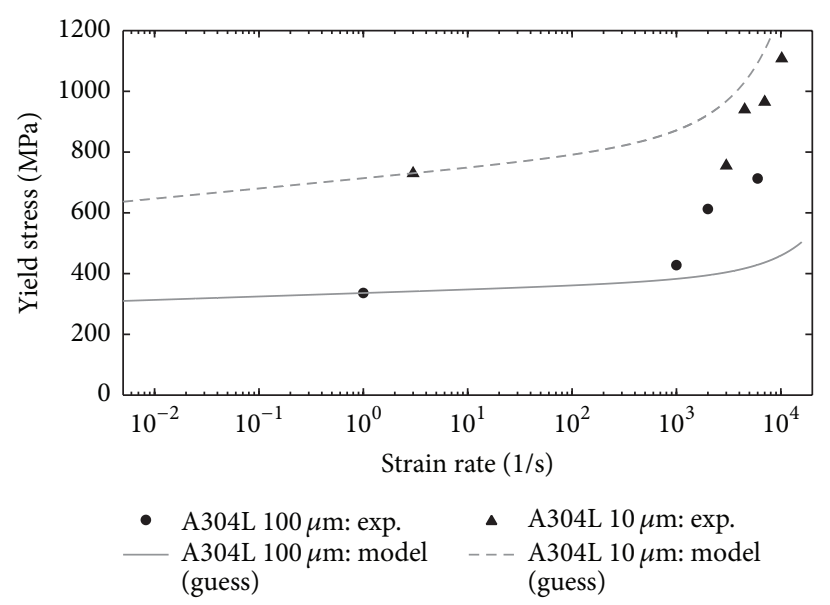

(a)

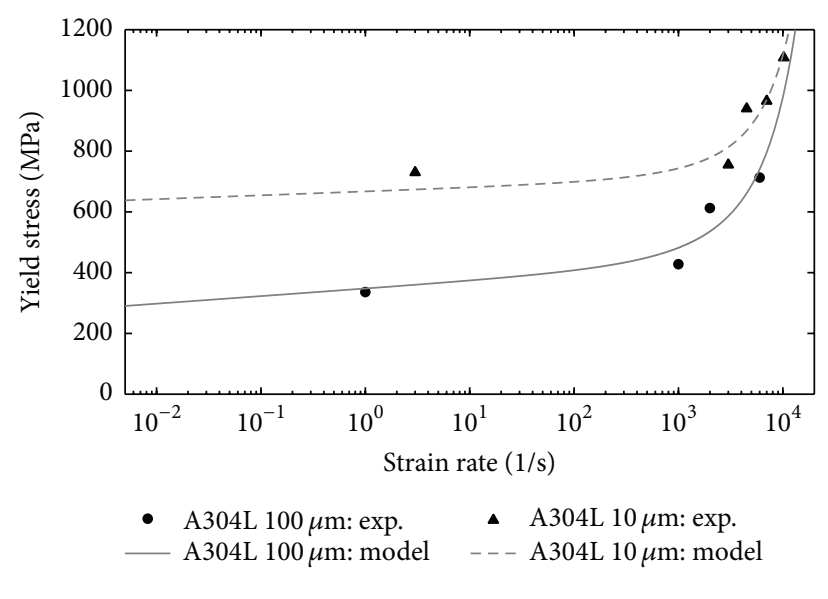

(b)

FIGURE 2: Comparison between experimental data (Couque [4]) and new modified Eyring equation for steel: (a) first-guess material constants and (b) optimized materials constants.

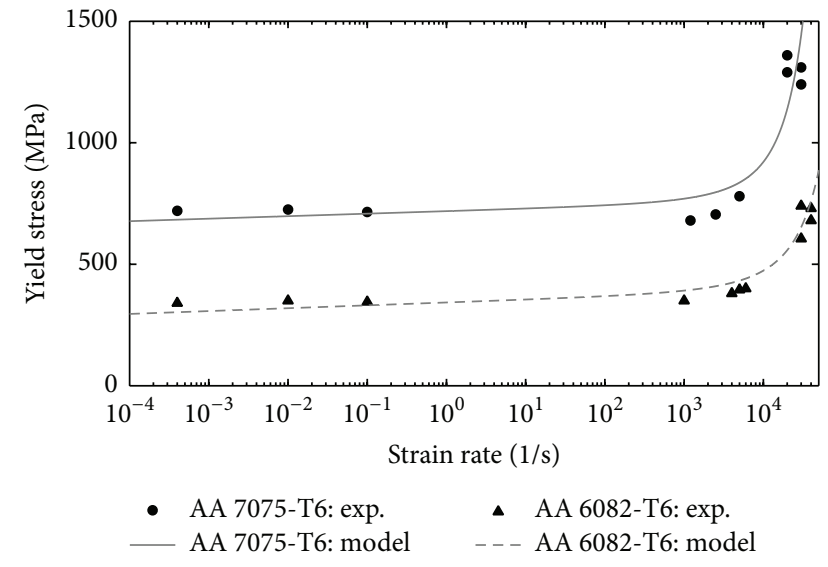

Figure 3: Comparison between experimental data (Moćko et al. [35]) and new modified Eyring equation for aluminum.

sensitivity of the two materials, except for the drop in the flow of AA 6082-T6 at around 1000/s, which should rather be attributed to the change of the testing machine as it is an uncommon behavior.

The modified Eyring equation fits well the flow stress at $5 \%$ of strain of CVD textured $\langle 011\rangle$ tungsten (Figure 4 ). The discrepancy obtained at low strain rates could rather be attributed to the unusual important jump of stress between $3 \times 10^{-4} \mathrm{~s}^{-1}$ and $5 \times 10^{-3} \mathrm{~s}^{-1}$.

Dealing with temperature effect on the strain rate sensitivity, Figure 5 compares the yield stress of annealed mild steel as predicted by (6) to the yield stress reported in [38]. For the two considered temperatures, that is, 293 and $493^{\circ} \mathrm{K}$, the modified Eyring equation fits well the experimental yield stress over a very wide range of strain rates (from $10^{-3}$ to $5 \times 10^{4} \mathrm{~s}^{-1}$ ). Figure 5 shows the capability of the new equation to catch the behavior for strain rates up to $5 \times 10^{4} \mathrm{~s}^{-1}$.

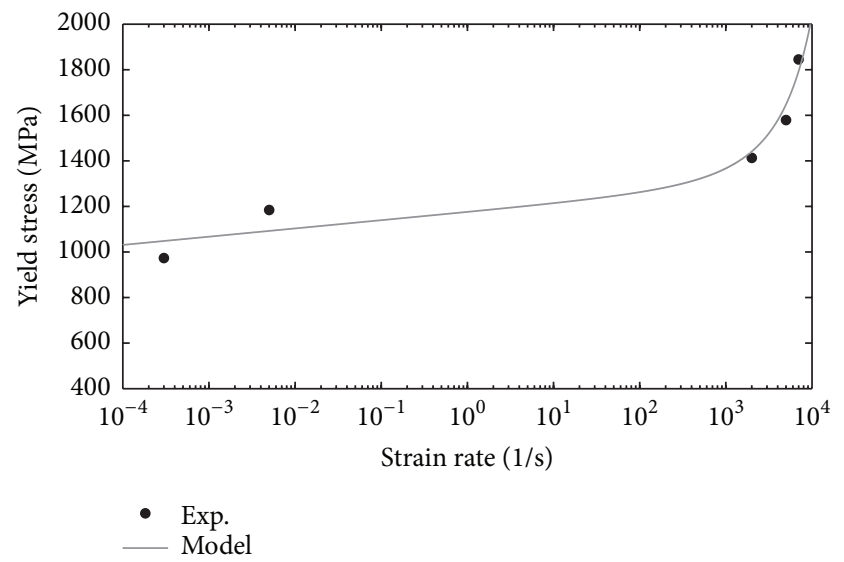

Figure 4: Comparison between experimental data (Subhash et al. [36]) and new modified Eyring equation for CVD textured $\langle 011\rangle$ tungsten.

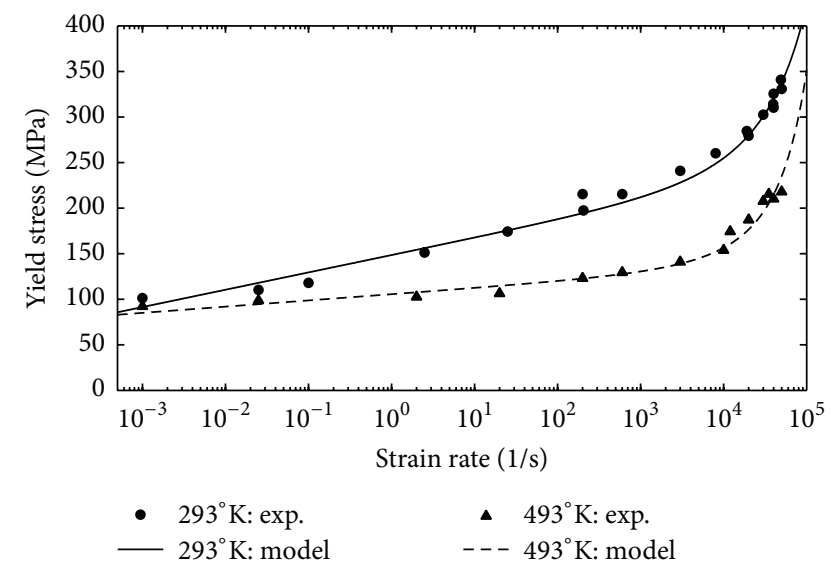

FIgURE 5: Comparison between experimental data (Clarke et al. [37] and Blazynski [38]) and new modified Eyring equation for annealed mild steel. 
TABLE 3: Optimized material constants for several metallic materials.

\begin{tabular}{lccc}
\hline & $\sigma_{0}(\mathrm{MPa})$ & $V_{0}\left(\mathrm{~nm}^{3}\right)$ & $\dot{\varepsilon}_{c}\left(\mathrm{~s}^{-1}\right)$ \\
\hline Copper $105 \mu \mathrm{m}$ & 96.4 & 2.35 & 2037 \\
Copper $26 \mu \mathrm{m}$ & 179.8 & 0.737 & 5919 \\
Copper $9 \mu \mathrm{m}$ & 271.6 & 0.612 & 7163 \\
A304L $100 \mu \mathrm{m}$ & 347.9 & 0.376 & 2946 \\
A304L $10 \mu \mathrm{m}$ & 667.5 & 0.737 & 2113 \\
AA 6082-T6 & 342.7 & 0.795 & 9598 \\
$\begin{array}{l}\text { AA 7075-T6 } \\
\text { CVD textured 〈011 }\rangle\end{array}$ & 718.6 & 0.907 & 3970 \\
tungsten & 1176 & 0.258 & 3158 \\
$\begin{array}{l}\text { Annealed mild steel } \\
\text { (293 K) }\end{array}$ & 148.5 & 0.492 & 89007 \\
$\begin{array}{l}\text { Annealed mild steel } \\
\text { (493 }{ }^{\circ} \text { K) }\end{array}$ & 105.6 & 1.370 & 25711 \\
$\begin{array}{l}\text { Ti-47Al-2Mn-2Nb alloy } \\
\text { (tensile yield) }\end{array}$ & 451.1 & 0.497 & 1462 \\
$\begin{array}{l}\text { Ti-47Al-2Mn-2Nb alloy } \\
\text { (tensile ultimate strength) }\end{array}$ & 481.8 & 0.495 & 590 \\
$\begin{array}{l}\text { Polyetheretherketone } \\
\text { (PEEK) [28] }\end{array}$ & $\mathbf{1 5 9}$ & $\mathbf{1 . 0 1}$ & $\mathbf{1 2 0 3 8}$ \\
\hline
\end{tabular}

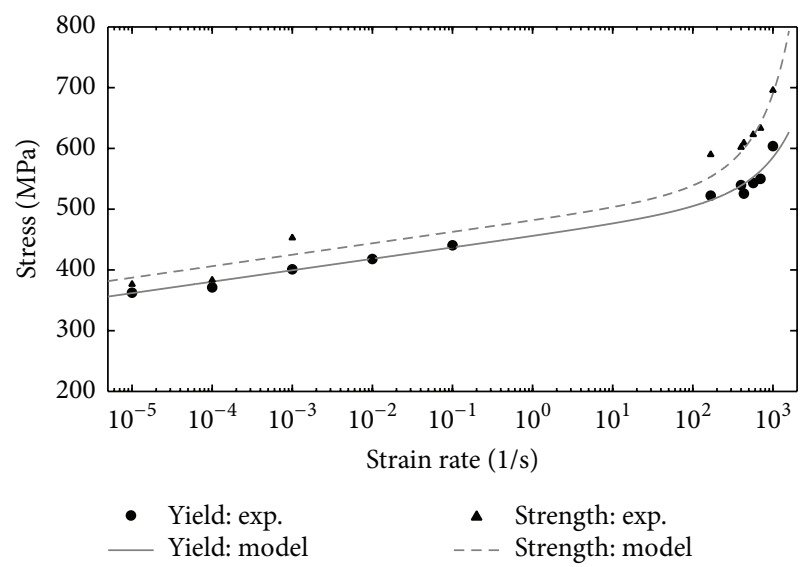

FIGURE 6: Comparison between experimental data (Wang et al. [39]) and new modified Eyring equation for Ti-47Al-2Mn-2Nb alloy.

The last example is dealing with tensile yield and ultimate stress of Ti-47Al-2Mn-2Nb (Figure 6). This example shows that the new equation can also fit the tensile behavior. Moreover, it is shown that it works for strain rates down to $10^{-5} \mathrm{~s}^{-1}$

The material parameters of the different metallic alloys are synthesized in Table 3 . They are also compared to the material parameters obtained for PEEK [28]. It is worth noting that the activation volume $V_{0}$ of metallic and polymeric materials is in the same range of $\left[0.25-2.4 \mathrm{~nm}^{3}\right]$. This gives a characteristic distance which is in the range of [6-14 $\AA]$. Studying copper over a wide temperature range, Suo et al. [40] reported that the activation volume is in the range of $10 b^{3}$.
Through multiple examples, the new modified Eyring constitutive equation has been showed here to have a great potential to model the strain rate sensitivity of the yield/flow stress over a very wide range of strain rates (from $10^{-5}$ to $5 \times 10^{4} \mathrm{~s}^{-1}$ ) using only three material constants.

\section{Conclusion}

In this work, a new modified Eyring constitutive equation, predicting the strain rate sensitivity of yield, was validated regarding the experimental yield stress of several metallic materials. This constitutive equation uses only three material constants which were determined using an optimization procedure. A methodology was established in order to obtain a first guess of the material constants, hence simplifying the optimization step. The modified Eyring equation fits well the experimental data on a very wide range of strain rates (over more than 8 decades). This is highly important result. Indeed, it is possible to fit the yield/flow stress on a so large strain rate range by using only three material constants.

\section{Conflict of Interests}

The author declares no conflict of interests.

\section{References}

[1] B. Song, K. Nelson, R. Lipinski, J. Bignell, G. Ulrich, and E. P. George, "Dynamic high-temperature testing of an iridium alloy in compression at high-strain rates," Strain, vol. 50, no. 6, pp. 539-546, 2014.

[2] B. Pramanik and P. R. Mantena, "Strain rate dependent ductileto-brittle transition of graphite platelet reinforced vinyl ester nanocomposites," Advances in Materials Science and Engineering, vol. 2014, Article ID 765698, 8 pages, 2014.

[3] S.-C. Woo, J.-T. Kim, C.-H. Cho, J.-Y. Kim, and T.-W. Kim, "The dynamic compressive behavior of armor structural materials in split Hopkinson pressure bar test," Journal of Strain Analysis for Engineering Design, vol. 48, no. 7, pp. 420-436, 2013.

[4] H. Couque, "The use of the direct impact Hopkinson pressure bar technique to describe thermally activated and viscous regimes of metallic materials," Philosophical Transactions of the Royal Society A: Mathematical, Physical and Engineering Sciences, vol. 372, no. 2023, Article ID 20130218, 10 pages, 2014.

[5] X. Guo, T. Heuzé, R. Othman, and G. Racineux, "Inverse identification at very high strain rate of the johnson-cook constitutive model on the Ti-6Al-4V alloy with a specially designed direct-impact Kolsky bar device," Strain, vol. 50, no. 6, pp. 527-538, 2014.

[6] G. Cowper and P. Symonds, "Strain hardening and strain-rate effects in the impact loading of cantilever beams," Tech. Rep., Division of Applied Mathematics, Brown University, 1952.

[7] F. J. Zerilli and R. W. Armstrong, "Dislocation-mechanicsbased constitutive relations for material dynamics calculations," Journal of Applied Physics, vol. 61, no. 5, pp. 1816-1825, 1987.

[8] J. A. Rodríguez-Martínez, A. Rusinek, and J. R. Klepaczko, "Constitutive relation for steels approximating quasi-static and intermediate strain rates at large deformations," Mechanics Research Communications, vol. 36, no. 4, pp. 419-427, 2009. 
[9] W. Moćko, J. Janiszewski, and M. Grazka, "Application of an extended Rusinek-Klepaczko constitutive model to predict the mechanical behavior of 6082-T6 aluminum under Taylor impact test conditions," The Journal of Strain Analysis for Engineering Design, vol. 48, no. 6, pp. 364-375, 2013.

[10] G. R. Johnson and W. H. Cook, "A constitutive model and data for metals subjected to large strains, high strain rates and high temperatures," in Proceedings of the 7th International Symposium on Ballistics, vol. 21, pp. 541-547, 1983.

[11] G. Ljustina, M. Fagerström, and R. Larsson, "Rate sensitive continuum damage models and mesh dependence in finite element analyses," The Scientific World Journal, vol. 2014, Article ID 260571, 8 pages, 2014.

[12] S. Hiermaier, Structures under Crash and Impact: Continuum Mechanics, Discretization and Experimental Characterization, Springer, New York, NY, USA, 2008.

[13] G.-H. Majzoobi, A. R. Hosseinkhani, S. Lahmi, M. K. Pipelzadeh, and S. J. Hardy, "Determination of the constants of material models at high strain rates and elevated temperatures using shot impact test," Journal of Strain Analysis for Engineering Design, vol. 49, no. 5, pp. 342-351, 2014.

[14] F. Li, X. Qi, and D. Xiang, "Finite element modeling of crack generation in laser shock peening processed airfoils," Advances in Materials Science and Engineering, vol. 2014, Article ID 812705, 10 pages, 2014.

[15] D. Notta-Cuvier, B. Langrand, E. Markiewicz, F. Lauro, and G. Portemont, "Identification of Johnson-Cook's viscoplastic model parameters using the virtual fields method: application to titanium alloy Ti6Al4V," Strain, vol. 49, no. 1, pp. 22-45, 2013.

[16] E. Etemadi, J. Z. Ashani, and M. V. Mousavi, "High strain rate and plastic deformation response of OFHC copper by finite element method," Advances in Mechanical Engineering, vol. 2014, Article ID 620854, 10 pages, 2014.

[17] S. Jafari, R. A. Alashti, and S. J. Hosseinipour, "Comparison of ductile fracture models on load bearing capacity of a dented aluminum pipe subjected to internal pressure," Arabian Journal for Science and Engineering, vol. 39, no. 11, pp. 8031-8049, 2014.

[18] P. Yibo, W. Gang, Z. Tianxing, P. Shangfeng, and R. Yiming, "Dynamic mechanical behaviors of 6082-T6 aluminum alloy," Advances in Mechanical Engineering, vol. 5, 8 pages, 2013.

[19] M. A. Iqbal, K. Senthil, P. Bhargava, and N. K. Gupta, "The characterization and ballistic evaluation of mild steel," International Journal of Impact Engineering, vol. 78, pp. 98-113, 2015.

[20] J. K. Holmen, O. S. Hopperstad, and T. Børvik, "Low-velocity impact on multi-layered dual-phase steel plates," International Journal of Impact Engineering, vol. 78, pp. 161-177, 2015.

[21] A. Iqbal, "Application of computational intelligence and knowledge-based system in predicting flow stress of AISI 4340," Arabian Journal for Science and Engineering, vol. 39, no. 11, pp. 8253-8263, 2014.

[22] V. V. Balandin, V. V. Balandin, A. M. Bragov, L. A. Igumnov, A. Y. Konstantinov, and A. K. Lomunov, "High-rate deformation and fracture of steel 09G2S," Mechanics of Solids, vol. 49, no. 6, pp. 666-672, 2014.

[23] H. Zhao and G. Gary, "The testing and behaviour modelling of sheet metals at strain rates from $10^{-4}$ to $10^{4} \mathrm{~s}^{-1}$, Materials Science and Engineering A, vol. 207, no. 1, pp. 46-50, 1996.

[24] B. J. Tuazon, K.-O. Bae, S.-H. Lee, and H.-S. Shin, "Integration of a new data acquisition/processing scheme in SHPB test and characterization of the dynamic material properties of high-strength steels using the optional form of Johnson-Cook model," Journal of Mechanical Science and Technology, vol. 28, no. 9, pp. 3561-3568, 2014.

[25] H. Couque, R. Boulanger, and F. Bornet, "A modified JohnsonCook model for strain rates ranging from $10^{-3}$ to $10^{5} \mathrm{~s}^{-1}$," Journal de Physique IV, vol. 134, pp. 87-93, 2006.

[26] V. Vilamosa, A. H. Clausen, E. Fagerholt, O. S. Hopperstad, and T. Børvik, "Local measurement of stress-strain behaviour of ductile materials at elevated temperatures in a split-hopkinson tension bar system," Strain, vol. 50, no. 3, pp. 223-235, 2014.

[27] D. N. Zhang, Q. Q. Shangguan, C. J. Xie, and F. Liu, "A modified Johnson-Cook model of dynamic tensile behaviors," Journal of Alloys and Compounds, vol. 619, pp. 186-194, 2015.

[28] Z. El-Qoubaa and R. Othman, "Characterization and modeling of the strain rate sensitivity of polyetheretherketone's compressive yield stress," Materials \& Design, vol. 66, pp. 336-345, 2015.

[29] H. Eyring, "Viscosity, plasticity, and diffusion as examples of absolute reaction rates," The Journal of Chemical Physics, vol. 4, no. 4, pp. 283-291, 1936.

[30] T. Ree and H. Eyring, "The relaxation theory of transport phenomena," in Rheology: Theory and Applications, F. R. Eirich, Ed., vol. 2, chapter 3, Academic Press, New York, NY, USA, 1958.

[31] D. Fotheringham, B. W. Cherry, and C. Bauwens-Crowet, "Comment on 'the compression yield behaviour of polymethyl methacrylate over a wide range of temperatures and strainrates," Journal of Materials Science, vol. 11, no. 7, pp. 1368-1371, 1976.

[32] D. G. Fotheringham and B. W. Cherry, "The role of recovery forces in the deformation of linear polyethylene," Journal of Materials Science, vol. 13, no. 5, pp. 951-964, 1978.

[33] J. Richeton, S. Ahzi, K. S. Vecchio, F. C. Jiang, and R. R. Adharapurapu, "Influence of temperature and strain rate on the mechanical behavior of three amorphous polymers: characterization and modeling of the compressive yield stress," International Journal of Solids and Structures, vol. 43, no. 7-8, pp. 2318-2335, 2006.

[34] Z. El-Qoubaa and R. Othman, "Tensile behavior of polyetheretherketone over a wide range of strain rates," International Journal of Polymer Science, vol. 2015, Article ID 275937, 9 pages, 2015.

[35] W. Moćko, J. A. Rodríguez-Martínez, Z. L. Kowalewski, and A. Rusinek, "Compressive viscoplastic response of 6082-T6 and 7075-T6 aluminium alloys under wide range of strain rate at room temperature: experiments and modelling," Strain, vol. 48, no. 6, pp. 498-509, 2012.

[36] G. Subhash, Y. J. Lee, and G. Ravichandran, "Plastic deformation of CVD textured tungsten-I. Constitutive response," Acta Metallurgica et Materialia, vol. 42, no. 1, pp. 319-330, 1994.

[37] K. D. Clarke, R. J. Comstock, M. C. Mataya, C. J. Tyne, and D. K. Matlock, "Effect of strain rate on the yield stress of ferritic stainless steels," Metallurgical and Materials Transactions A: Physical Metallurgy and Materials Science, vol. 39, no. 4, pp. 752762, 2008.

[38] T. Z. Blazynski, Materials at High Strain Rates, Elsevier Applied Science, New York, NY, USA, 1987.

[39] Y. Wang, D. Lin, Y. Zhou, Y. Xia, and C. C. Law, "Dynamic tensile properties of Ti-47Al-2Mn-2Nb alloy," Journal of Materials Science, vol. 34, no. 3, pp. 509-513, 1999.

[40] T. Suo, L. Ming, F. Zhao, Y. Li, and X. Fan, "Temperature and strain rate sensitivity of ultrafine-grained copper under uniaxial compression," International Journal of Applied Mechanics, vol. 5, no. 2, Article ID 1350016, 15 pages, 2013. 

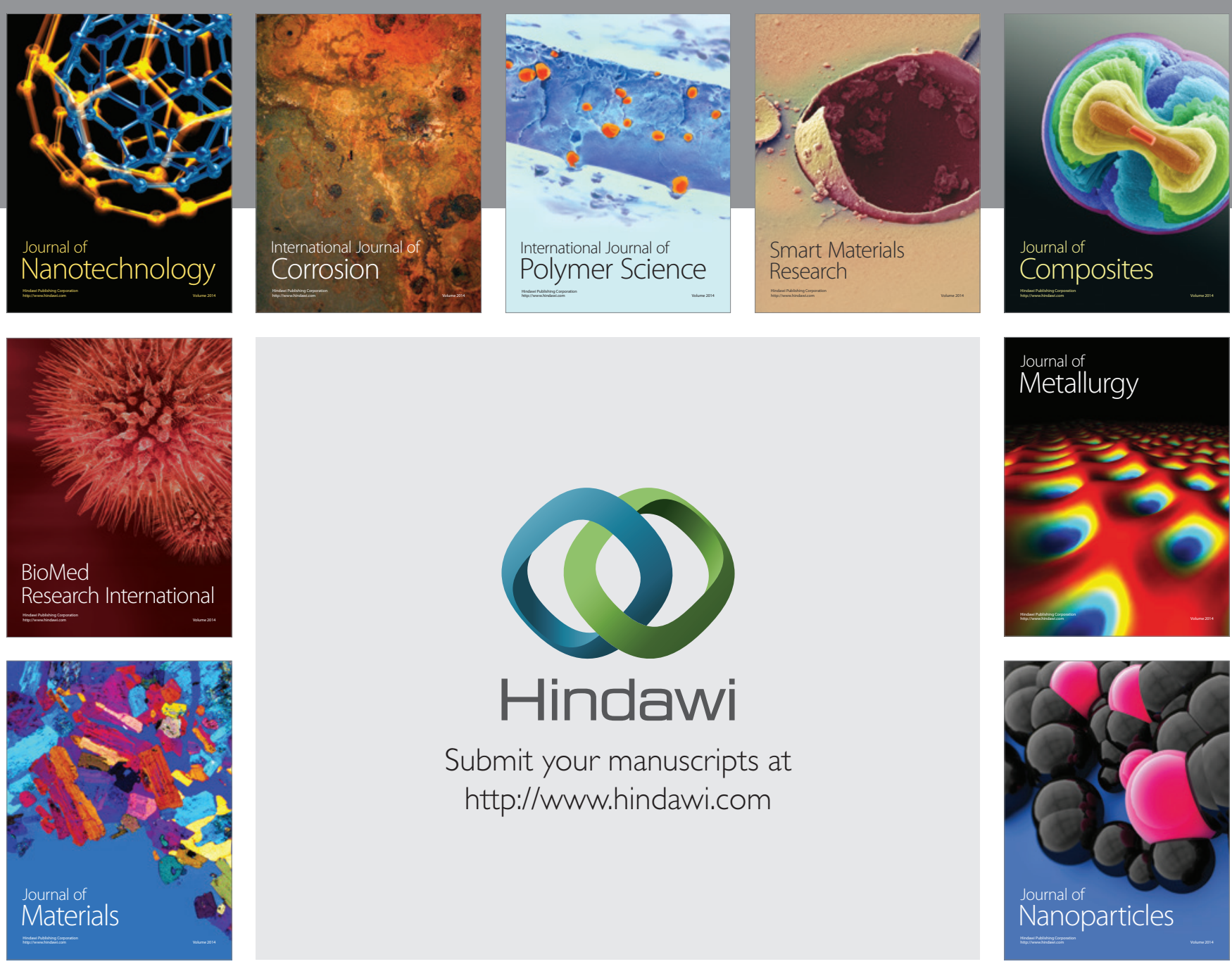

Submit your manuscripts at http://www.hindawi.com
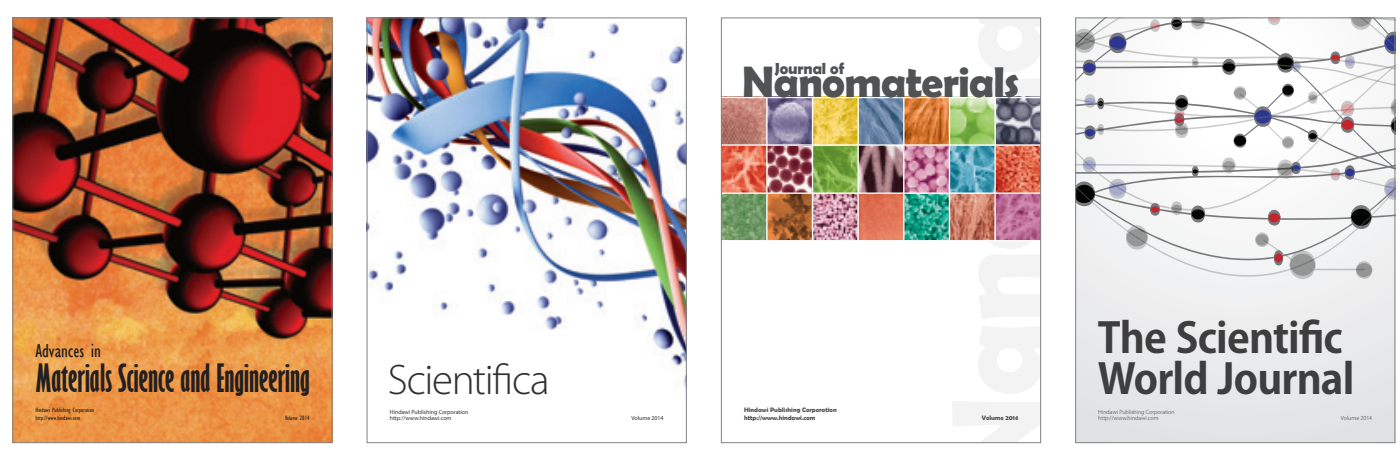

\section{The Scientific World Journal}
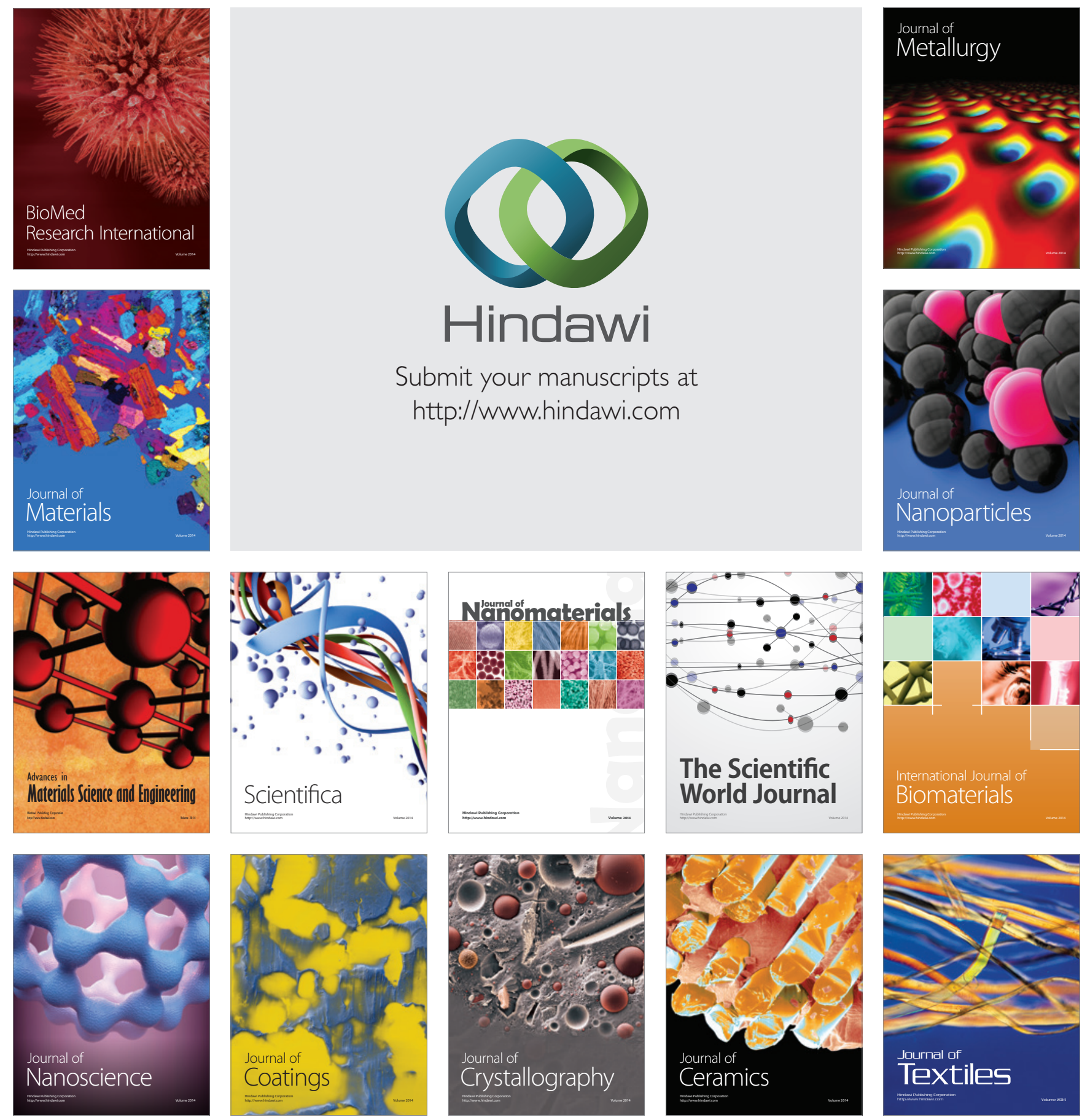